\title{
HUBUNGAN ANTARA KUALITAS TIDUR DENGAN ACNE VULGARIS PADA MAHASISWA FAKULTAS KEDOKTERAN UMUM UNIVERSITAS MALAHAYATI ANGKATAN 2019
}

\author{
Eka Silvia1, Arti Febriyani' ${ }^{2}$, Resati Nando ${ }^{3}$, Aulia Riza ${ }^{4}$ \\ ${ }^{1}$ Departemen Fisiologi Fakultas Kedokteran Universitas Malahayati \\ ${ }^{2}$ Departemen Immunologi Fakultas Kedokteran Universitas Malahayati \\ ${ }^{3}$ Departemen Dermatologi RS Pertamina Bintang Amin \\ ${ }^{4}$ Program Studi Kedokteran Fakultas Kedokteran, Universitas Malahayati
}

[email korespondensi: auliarizaaa@gmail.com]

\begin{abstract}
The Correlation Between Sleep Quality And Acne Vulgaris In Students Of 2019 At Medical Education Program, Malahayati University. Acne Vulgaris (AV) or pimple is chronic inflammatory disease of the pilosebaceous gland. One of several ways to prevent acne vulgaris is to improve sleep quality. Previous study proved that good quality of sleep can suppresses excessive production of androgen hormones which take part in acne vulgaris incidence. Determine the correlation between sleep quality with acne vulgaris in students of 2019 at Medical Education Study Program, Malahayati University. Observational analytics with cross sectional method using a total sampling of 157 whole samples divided into 112 samples positive acne vulgaris and 45 samples negative acne vulgaris. The data was collected an November 2019. This research was conducted at Malahayati University, Bandar Lampung. Data has been by the chi-square test using the SPSS. Obtained research respondents totaling 157 students with poor sleep quality were 119 respondents $(75,8 \%)$, good sleep quality 38 respondents $(24,2 \%)$. Students with acne vulgaris positive totaled 112 respondents $(71,3 \%)$, acne vulgaris negative 45 respondents $(28,7 \%)$. Statiscal analysis used Chi-Square showed that a $p$-value of 0,000 ( $p$-value $<0,005$ ) with Odds Ratio $(O R)=33,214$. There is a correlation of the sleep quality and acne vulgaris in students of 2019 at medical education program, Malahayati University.
\end{abstract}

Keyword : Sleep Quality, Acne Vulgaris.

\begin{abstract}
ABSTRAK: Hubungan Antara Kualitas Tidur Dengan Acne Vulgaris Pada Mahasiswa Fakultas Kedokteran Umum Universitas Malahayati Angkatan 2019. Acne vulgaris (AV) atau jerawat adalah peradangan kronik dari kelenjar pilosebaseus. Salah satu tindakan pencegahan untuk mengatasi acne vulgaris adalah dengan memperbaiki kualitas tidur. Hal ini sudah terbukti pada penelitianpenelitian sebelumnya bahwa mempertahankan kualitas tidur yang baik dapat menekan hormon androgen yang berperan dalam timbulnya acne vulgaris. Mengetahui hubungan antara kualitas tidur dengan acne vulgaris pada mahasiswa fakultas kedokteran umum universitas malahayati angkatan 2019. Analitik observasional dengan menggunakan pendekatan metode cross sectional menggunakan teknik total sampling sebanyak 157 sampel keseluruhan di bagi menjadi 112 sampel dengan acne vulgaris positif dan 45 sampel dengan acne vulgaris negatif. Pengambilan data dimulai pada bulan November 2019. Penelitian ini dilakukan di Universitas Malahayati Bandar Lampung. Data statistik uji chisquare menggunakan SPSS. Didapatkan responden penelitian berjumlah 157 mahasiswa dengan kualitas tidur buruk berjumlah 119 responden (75,8\%), kualitas tidur baik berjumlah 38 responden (24,2\%). Mahasiswa dengan acne vulgaris positif berjumlah 112 responden $(71,3 \%)$, acne vulgaris negatif berjumlah 45 responden $(28,7 \%)$. Analisis statistik menggunakan uji Chi-Square menunjukan p-value sebesar 0,000 dengan Odds Ratio $(\mathrm{OR})=33,214$. Terdapat hubungan antara kualitas tidur dengan acne vulgaris pada mahasiswa fakultas kedokteran umum universitas malahayati angkatan 2019.
\end{abstract}

Kata Kunci: Kualitas Tidur, Acne vulgaris. 


\section{PENDAHULUAN}

Acne vulgaris adalah kelainan pada kelenjar pilosebaceous yang biasanya muncul di bagian wajah, tubuh bagian atas dan lengan atas. Acne vulgaris merupakan penyakit kulit yang bisa sembuh sendiri, akan tetapi acne vulgaris memiliki konsekuensi jangka panjang yang bisa menyebabkan pembentukan bekas luka permanen. Acne vulgaris dan juga bekas jerawat dapat mempengaruhi efek psikososial seperti rasa malu, isolasi sosial, rendah diri, kecemasan, frustasi, depresi, bahkan yang paling fatal adalah keinginan untuk bunuh diri (Nurhadi et al, 2019).

Kualitas tidur adalah kepuasan seseorang terhadap tidur, sehingga seseorang tersebut tidak memperlihatkan rasa lelah, lesu, gelisah, dan apatis (Djunarko et al, 2018). Kualitas tidur terdiri dari aspek kualitatif dan kuantitatif tidur, seperti waktu yang diperlukan untuk bisa tertidur, lamanya waktu tidur, kedalaman tidur, kepulasan dan frekuensi terbangun. Pola tidur yang baik dan teratur memberikan efek yang bagus terhadap kesehatan (Wicaksono, 2019).

Prevalensi acne vulgaris di dunia di perkirakan lebih dari 60 juta. Di Amerika acne vulgaris merupakan penyakit yang paling umum terjadi, di tandai dengan adanya peradangan baik terbuka maupun tertutup, sekitar $60 \%-70 \%$ penderita acne vulgaris ditandai dengan ditemukannya komedo, pustula, papula dan nodul. $20 \%$ diantaranya memiliki jerawat dengan derajat berat. Sehingga dapat berakibat pada fisik dan mental yang menimbulkan jaringan parut permanen (Manarisip et al, 2015).

Prevalensi acne vulgaris di Indonesia terjadi sekitar $85 \%-100 \%$. Acne vulgaris merupakan penyakit yang paling umum terjadi pada remaja. Prevalensi acne vulgaris pada remaja indonesia cukup tinggi yaitu berkisar antara 47\%-90\% selama masa remaja. Prevalensi tertinggi pada wanita usia 14-17 tahun, berkisar $83-85 \%$, dan pada pria usia 16-19 tahun dengan berkisar 95-100\%. Dan diperoleh $4,71 \%$ dari kasus acne vulgaris disebabkan oleh ketidakseimbangan hormon (Sibero et al, 2019).

Prevalensi acne vulgaris di Rumah Sakit Abdul Moeloek Bandar Lampung terdapat angka kejadian acne vulgaris dengan derajat ringan $50 \%$, dan derajat acne berat $50 \%$. Penyebab acne masih belum dapat dipahami sepenuhnya. Salah satu faktor yang berperan terhadap terjadinya acne vulgaris adalah meningkatnya sekresi sebum. Sebum sendiri diproduksi oleh kelenjar sebasea. Sekresi sebum meningkat akibat adanya sekresi hormon androgen yang tinggi (Sari et al, 2018).

Sintesis hormon androgen dapat ditekan dengan adanya hormon melatonin. Hormon melatonin berfungsi untuk menginduksi tidur dan dapat meningkatkan kualitas tidur. Acne vulgaris mempunyai efek yang dapat merusak kepercayaan diri seseorang karena menyerang daerah yang mudah terlihat dan penting dalam penampilan seseorang. Tindakan pengobatan dapat dilakukan untuk mengatasi acne vulgaris, namun diperlukan juga tindakan pencegahan yang salah satunya adalah dengan memperbaiki kualitas tidur. Penelitian-penelitian sebelumnya mempertahankan kualitas tidur yang baik dimana sekresi melatonin yang cukup, dapat menekan produksi hormon androgen yang berperan dalam timbulnya acne vulgaris (Djunarko et al, 2018).

Berdasarkan uraian tersebut, peneliti tertarik melakukan penelitian lebih lanjut tentang : Hubungan Antara Kualitas Tidur Dengan Acne Vulgaris Pada Mahasiswa Fakultas Kedokteran Umum Universitas Malahayati Angkatan 2019.

\section{METODE}

Jenis penelitian ini adalah analitik observasional dengan menggunakan pendekatan metode cross sectional menggunakan teknik total sampling sebanyak 157 sampel keseluruhan di bagi menjadi 112 sampel dengan acne vulgaris positif dan 45 sampel dengan acne vulgaris negatif yang memenuhi kriteria inklusi dan eksklusi. Pengambilan data dimulai pada bulan November 2019. Data yang digunakan 
yaitu data primer yaitu berupa kuesioner PSQI (Pittsburgh sleep quality index). Penelitian ini dilakukan di Universitas Malahayati Bandar

\section{HASIL}

Tabel 1 memperlihatkan distribusi frekuensi responden berdasarkan kualitas tidur diketahui dari 157 responden didapatkan responden
Lampung. Data di evaluasi dengan statistik uji chi-square menggunakan program komputer SPSS.

yang kualitas tidur buruk berjumlah 119 responden $(75,8 \%)$ lebih banyak dibandingkan kualitas tidur baik sebanyak 38 responden (24,2\%).

Tabel 1. Distribusi Frekuensi Sampel Berdasarkan Kualitas Tidur pada Mahasiswa Fakultas Kedokteran Umum Universitas Malahayati Angkatan 2019.

\begin{tabular}{lcc}
\hline Kualitas Tidur & Frekuensi & Persentase (\%) \\
\hline Buruk & 119 & $75,8 \%$ \\
Baik & 38 & $24,2 \%$ \\
\hline Total & 157 & $100 \%$ \\
\hline
\end{tabular}

Tabel 2 memperlihatkan distribusi frekuensi responden berdasarkan Acne vulgaris diketahui dari 157 responden didapatkan responden dengan Acne vulgaris positif berjumlah 112

responden $\quad(71,3 \%) \quad$ sedangkan responden dengan Acne vulgaris negatif berjumlah 45 responden $(28,7 \%)$.

Tabel 2. Distribusi Frekuensi Sampel Berdasarkan Acne vulgaris pada Mahasiswa Fakultas Kedokteran Umum Universitas Malahayati Angkatan 2019.

\begin{tabular}{lcc}
\hline Acne Vulgaris & Frekuensi & Persentase (\%) \\
\hline Acne vulgaris positif & 112 & $71,3 \%$ \\
Acne vulgaris negatif & 45 & $28,7 \%$ \\
\hline Total & 157 & $100 \%$ \\
\hline
\end{tabular}

Tabel 3 diketahui bahwa dari 119 sampel dengan kualitas tidur buruk yang mengalami acne vulgaris positif sebanyak 105 sampel $(88,2 \%)$ dan yang mengalami acne vulgaris negatif sebanyak 14 sampel $(11,8 \%)$.

Tabel 3. Hubungan Antara Kualitas Tidur dengan Acne Vulgaris

\begin{tabular}{|c|c|c|c|c|c|c|c|c|}
\hline \multirow{3}{*}{$\begin{array}{l}\text { Kualitas } \\
\text { Tidur }\end{array}$} & \multicolumn{4}{|c|}{ Acne vulgaris } & \multirow{2}{*}{\multicolumn{2}{|c|}{ Jumlah }} & \multirow{3}{*}{$\begin{array}{l}\text { OR (CI } \\
95 \%)\end{array}$} & \multirow{3}{*}{$\begin{array}{c}p- \\
\text { value }\end{array}$} \\
\hline & \multicolumn{2}{|c|}{ Acne positif } & \multicolumn{2}{|c|}{ Acne negatif } & & & & \\
\hline & $\mathbf{n}$ & $\%$ & $n$ & $\%$ & $n$ & $\%$ & & \\
\hline Buruk & 105 & $88,2 \%$ & 14 & $11,8 \%$ & 119 & $100 \%$ & 33,214 & 0,000 \\
\hline Baik & 7 & $18,4 \%$ & 31 & $81,6 \%$ & 38 & $100 \%$ & $\begin{array}{c}(12,319- \\
89,549)\end{array}$ & \\
\hline Total & 112 & $71,3 \%$ & 45 & $28,7 \%$ & 157 & $100 \%$ & & \\
\hline
\end{tabular}

Sedangkan dari 38 sampel dengan kualitas tidur baik yang mengalami acne vulgaris positif sebanyak 7 sampel $(18,4 \%)$ dan yang mengalami acne vulgaris negatif sebanyak 31 sampel $(81,6 \%)$. Dari hasil analisis chi-square didapatkan nilai p-value yakni 0,000 dan Odds 
Ratio 33,214. Hal ini menunjukkan terdapat hubungan antara kualitas tidur dengan acne vulgaris.

\section{PEMBAHASAN}

Kualitas tidur adalah kepuasan seseorang terhadap tidur, sehingga seseorang tersebut tidak memperlihatkan rasa lelah, lesu, gelisah, dan apatis. Kualitas tidur terdiri dari aspek kualitatif dan kuantitatif tidur, seperti waktu yang diperlukan untuk bisa tertidur, lamanya waktu tidur, kedalaman tidur, kepulasan dan frekuensi terbangun. Pola tidur yang baik dan teratur memberikan efek yang bagus terhadap kesehatan (Wicaksono, 2019).

Berdasarkan hasil penelitian yang dilakukan pada mahasiswa Fakultas Kedokteran Umum Universitas Malahayati angkatan 2019 didapatkan sampel dengan rentang usia 18-20 tahun diperoleh kualitas tidur buruk berjumlah 119 sampel $(75,8 \%)$ dan kualitas tidur baik sebanyak 38 sampel $(24,2 \%)$. Hasil penelitian ini sejalan dengan penelitian yang dilakukan oleh Djunarko (2018) dengan judul Hubungan kualitas tidur dengan kejadian acne vulgaris pada laki-laki pekerja swasta studi pada karyawan perusahaan swasta di wilayah kota Semarang didapatkan hasil dari 97 sampel, terdiri dari 60 sampel $(61,9 \%)$ dengan kualitas tidur buruk, serta 37 sampel $(38,1 \%)$ dengan kualitas tidur baik (Djunarko et al, 2018).

Dari hasil penelitian ini didapatkan sampel dengan kualitas tidur buruk lebih banyak dibandingkan dengan sampel kualitas tidur baik. Hal ini sesuai dengan kuesioner yang diisi oleh mahasiswa Fakultas Kedoteran Umum Universitas Malahayati angkatan 2019 bahwa masih banyak sampel yang mengalami kesulitan dalam memulai tidur, durasi tidur yang singkat, dan mengalami gangguan ketika tidur seperti : terbangun ditengah malam atau terlalu dini, tidak mampu tidur nyenyak, kedinginan atau kepanasan, mimpi buruk, batuk atau mengorok sehingga mahasiswa hanya memiliki durasi tidur sebanyak 4-6 jam. Meskipun banyak yang mengalami kesulitan tidur, dari hasil kuesioner tidak didapatkan mahasiswa yang menggunakan obat tidur untuk mengatasi masalah tidurnya (Data Primer).

Acne Vulgaris (AV) atau jerawat merupakan peradangan kronis folikel pilosebasea dengan penyebab multifactor dan manifestasi klinis berupa komedo, papul, pustul, nodul, serta kista. Acne Vulgaris disebabkan oleh banyak faktor antara lain : sebum, bakteria, herediter, hormon, iklim, psikis, kosmetika (Harahap, 2015).

Berdasarkan hasil penelitian yang dilakukan pada mahasiswa Fakultas Kedokteran Umum Universitas Malahayati angkatan 2019 didapatkan sampel dengan rentang usia 18-20 tahun diperoleh acne vulgaris positif berjumlah 112 sampel $(71,3 \%)$ dan acne vulgaris negatif berjumlah 45 sampel $(28,7 \%)$. Hasil penelitian ini sejalan dengan penelitian yang dilakukan dengan judul Hubungan kualitas tidur dengan kejadian acne vulgaris pada laki-laki pekerja swasta studi pada karyawan perusahaan swasta di wilayah kota Semarang didapatkan hasil dari 97 sampel, terdiri dari 84 sampel $(86,6 \%)$ dengan acne vulgaris positif, serta 13 sampel $(13,4 \%)$ dengan acne vulgaris negatif (Djunarko et al, 2018).

Pada umumnya acne vulgaris dimulai pada usia 12-15 tahun, dengan puncak tingkat keparahan pada usia 17-21 tahun. Acne vulgaris adalah penyakit terbanyak remaja usia 15-18 tahun. Pada waktu pubertas terjadi peningkatan hormon androgen yang menyebabkan hiperplasia dan hipertrofi glandula sebasea, sehingga dapat mengakibatkan terjadinya acne vulgaris (Bernadette \& Wasiaatmaja, 2015).

Salah satu faktor yang berperan terhadap terjadinya acne vulgaris adalah meningkatnya sekresi sebum. Sebum sendiri diproduksi oleh kelenjar sebasea. Sekresi sebum meningkat akibat adanya sekresi hormon androgen yang tinggi (Djunarko et al, 2018).

Berdasarkan Hasil penelitian yang dilakukan pada Mahasiswa Fakultas Kedokteran Umum Universitas Malahayati Angkatan 2019. Didapatkan 
pada kelompok yang kualitas tidur buruk sebagaian besar berpengaruh terhadap acne vulgaris sebanyak $105(88,2 \%)$ responden. Nilai $\mathrm{p}=0,000$ artinya hipotesis diterima sehingga dapat disimpulkan dari uji chi-Square tersebut adalah terdapat hubungan antara kualitas tidur dengan acne vulgaris pada mahasiswa Fakultas Kedokteran Umum Universitas Malahayati Angkatan 2019. Nilai Odds Ratio didapatkan 33,214 dengan confidence interval (CI) $95 \%$ sebesar $(2,919-18,009)$, artinya responden yang kualitas tidurnya buruk beresiko 33,214 kali lebih besar untuk mengalami acne vulgaris dari pada responden dengan kualitas tidur baik.

Hasil kuesioner yang dibagikan pada mahasiswa Fakultas Kedokteran Umum Universitas Malahayati Angkatan 2019 berdasarkan lembar cheklist didapatkan rata-rata yang mengalami acne vulgaris yaitu responden yang kualitas tidur buruk.

Penelitian ini sejalan dengan penelitian yang dilakukan (Djunarko et al, 2018) dengan judul Hubungan kualitas tidur dengan kejadian acne vulgaris pada laki-laki pekerja swasta studi pada karyawan perusahaan swasta di wilayah kota Semarang, yang menunjukan bahwa terdapat hubungan yang secara statistik signifikan antara kualitas tidur dengan kejadian acne vulgaris pada laki-laki pekerja swasta studi pada karyawan perusahaan swasta di wilayah kota Semarang. Hasil penelitian ini juga sejalan dengan penelitian yang dilakukan Sonya (2017) dengan judul Hubungan kualitas tidur dengan kejadian acne vulgaris pada siswi SMA Al-Kautsar Bandar Lampung, yang menunjukan terdapat hubungan yang secara statistik signifikan antara kualitas tidur dengan kejadian acne vulgaris di SMA AlKautsar Bandar Lampung (Sonya, 2017).

Hasil tersebut sesuai dengan teori yang ada. Kualitas tidur yang buruk menyebabkan penurunan hormon melatonin. Hormon melatonin dikeluarkan pada malam hari oleh kelenjar pineal yang berada di hipotalamus diatas chiasma opticum. Pada siang hari ketika kelenjar pineal tidak atif melatonin tertekan. Ketika hari menjadi gelap, level plasma naik dengan drastis dan rasa kantuk datang sehingga efek chronobiotic dari melatonin diasosiasikan dengan ritma sirkardian yang mengatur siklus tidur dan bangun (Djunarko et al, 2018).

Jam tidur yang baik yaitu dimulai pukul 08.00 malam hingga tengah malam untuk mendapatkan tidur yang nyenyak dan mimpi indah. Jika tidur larut malam di atas jam 12 malam, kebiasaan ini akan memberikan dampak buruk pada kesehatan. Tidur terlalu larut memiliki kaitan signifikan dengan penurunan hormon melatonin (National Sleep Foundation, 2015).

Hormon melatonin sendiri berfungsi untuk menekan sintesis androgen. Rendahnya hormon melatonin menyebabkan peningkatan sintesis hormon androgen. Peningkatan sintesis hormon androgen menyebabkan meningkatnya sekresi kelenjar sebum yang mengakibatkan terjadinya acne vulgaris (Djunarko et al, 2018).

\section{KESIMPULAN}

Berdasarkan hasil analisis dan pembahasan dalam penelitian ini, maka dapat diambil kesimpulan hasil analisis menggunakan chi-square, didapatkan $\mathrm{p}$-value $=0,000$ sehingga $\mathrm{p}$ value $(\leq 0,005)=0,000 \leq 0,005$ yang artinya Ho ditolak. Jadi dapat disimpulkan terdapat hubungan yang bermakna antara kualitas tidur dengan acne vulgaris pada mahasiswa Fakultas Kedokteran Umum Universitas Malahayati Angkatan 2019 dengan Odds Ratio $(O R)=33,214$ yang berarti peluang responden dengan kualitas tidur buruk berisiko tiga puluh tiga kali untuk menderita acne vulgaris.

\section{SARAN}

Edukasi kepada mahasiswa yang memiliki risiko tinggi menderita acne vulgaris untuk tidur dengan durasi yang cukup dan mematikan lampu ketika hendak tidur.

\section{DAFTAR PUSTAKA}

Bernadette, I., Wasiaatmaja, M.S. 2015. Ilmu Penyakit Kulit dan 
Kelamin Edisi 7. Jakarta: Badan Penerbit FKUI. Hal. 288-290.

Djunarko, J.C., Widayati, R.I. and Julianti, H.P. 2018. Hubungan Kualitas Tidur Dengan Kejadian Akne Vulgaris Pada Laki-laki Pekerja Swasta Studi Pada Karyawan Perusahaan Swasta Di Wilayah Kota Semarang. Jurnal Kedokteran Diponegoro, 7(2), pp.1000-1011.

Harahap, M. 2015. Ilmu Penyakit Kulit. Jakarta: Hipokrates.

Manarisip, C.K., Kepel, B.J. and Rompas, S.S. 2015. Hubungan Stres dengan Kejadian Akne Vulgaris Pada Mahasiswa Semester V (Lima) Program Studi Ilmu Keperawatan Fakultas Kedokteran Universitas Sam Ratulangi Manado. Jurnal Keperawatan, 3(1).

National Sleep Foundation. adolescent sleep needs and pattern. National Sleep Foundation; $2015 . \quad$ Retrieved from www.sleepfoundation.org.

Notoatmodjo, S. 2018 Metodologi Penelitian Kesehatan. Jakarta: Rineka Cipta.

Nurhadi, S., Praharsini, I.G.A.A. and Wiraguna, A.A. 2019. Elevated homeostatic model assessment of insulin resistance level increases the risk of acne. Journal of General-Procedural Dermatology \& Venereology Indonesia. pp.21-28.

Sari, HK. 2018. Perbandingan Kualitas Hidup Akne Vulgaris Tipe Ringan Dengan Akne Vulgaris Tipe Berat Di Rsud. Dr. H. Abdul Moeloek Provinsi Lampung 2018. Bandar Lampung: Universitas Malahayati.

Sibero, H.T., Sirajudin, A. and Anggraini, D.I. 2019. Prevalensi dan Gambaran Epidemiologi Akne Vulgaris di Provinsi Lampung. Jurnal Kedokteran Universitas Lampung, 3(2): 308-312.

Sonya, Y. 2017. Hubungan kualitas tidur dengan kejadian acne vulgaris pada siswi SMA AlKautsar Bandar Lampung tahun
2017 [skripsi]. Bandar Lampung: Universitas Malahayati.

Wicaksono, D.W. 2019. Analisis Faktor Dominan yang berhubungan Dengan Kualitas Tidur Pada Mahasiswa Fakultas Keperawatan Universitas Airlangga. Fundamental and Management Nursing Journal, 1(1): 46-58. 